\title{
EFFECT OF THE USE OF CRUMB RUBBER IN CONVENTIONAL BITUMEN ON THE MARSHALL STABILITY VALUE
}

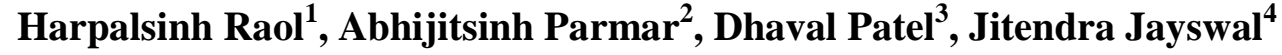 \\ ${ }^{I}$ Scholar, Transportation Engineering, GEC Modasa, Gujarat, India \\ ${ }^{2}$ Assistant Professor, SVBIT, Gandhinagar, Gujarat, India \\ ${ }^{3,4}$ Scholar, WRM Engineering, LDCE, Gujarat, India
}

\begin{abstract}
In today's era, solid waste management is the thrust area. Out of this various waste materials, plastic waste, tyre waste and municipal solid waste are of great concern. On the other side, the road traffic is increasing. The traffic intensity isalso increasing. The load bearing capacities of the road are to be increased. Our present work is helping to take care of both these aspects.Plastic waste, consisting of carry bags, cups, thermocoles, etc. can be used as a coating over aggregate and this coated stone can be used for road construction. Secondly the waste tires are powdered and the powder is blended with bitumen and this blend is used along with plastic coated aggregate. The mix polymer coated aggregate and tyre modified bitumen have shown higher strength. Use of this mix for road construction helps to use both plastics waste and tyre waste.Stone aggregate is coated with the molten waste plastics. The coating of plastics reduces the porosity, absorption of moisture and improves soundness.The polymer coated aggregate bitumen mix forms better material for flexible pavement construction as the mix shows higher Marshall Stability value and suitable Marshall Coefficient. Moreover the polymer coated aggregate helps to use Crumb rubber modified bitumen resulting in better result. Moreover the polymer coated aggregate helps to use Crumb rubber modified bitumen resulting in better result.Crumb Rubber Modified Bitumen (CRMB) is hydrocarbon binder obtained through physical and chemical interaction of crumb rubber (produced by recycling of used tires) with bitumen and some specific additives. The Flextal range of CRMB offers binders which are stable and easy to handle with enhanced performances.( www.total.co.in)[1]
\end{abstract}

Keywords:CRMB, Pavement, Bitumen, Crumb Rubber, and Marshall Stability Value

\section{INTRODUCTION}

The most dominant mode of the transport in India is the Road Transport, carrying close to $90 \%$ of the passenger traffic \& $70 \%$ of the freight transport. In India, flexible pavement type of construction is preferred over the rigid pavement type of construction due to its various advantages such as low initial cost, maintenance cost, etc.Therefore, among the surfaced roads, maximum is the contribution of the bituminous pavements. In spite of the prominence of the surface transport, most of the roads are poorly managed and badly maintained.Bitumen is used as binder \& water proofing material for construction of roads, pavements \& air field surfacing for several years. The demand of bitumen has increased tremendously because of rapid urbanization in recent years. The objective can be achieved by enhancing the durability of existing road surfacing which will result in reducing maintenance $\&$ resurfacing operations.

Hence, the modification of bitumen to meet the required performance standards of the pavement appears to be logical $\&$ economical approach. Bituminous pavement fails to give the expected service life under adverse climate, environmental\& traffic conditions. The use of crumb-rubber in bitumen modification helps in achieving better performance of wearing courses.

The advantages of modified bitumen can include one or more of the following for road works.

- Lower susceptibility to daily \& seasonal temperature variations.

- Higher resistance to deformation at elevated pavement temperature.

- Better age resistance properties.

- Higher fatigue life of mixes.

- Better adhesion between aggregates \& binder.

- Prevention of cracking \& reflective cracking.

- Overall improved performance in extreme climatic conditions \& under heavy traffic conditions.

\section{OBJECTIVE}

The advantages of modified bitumen can include one or more of the following for road works.

- Lower susceptibility to daily \& seasonal temperature variations.

- Higher resistance to deformation at elevated pavement temperature. 
- Better age resistance properties.

- Higher fatigue life of mixes.

- Better adhesion between aggregates \& binder.

- Prevention of cracking \& reflective cracking.

- Overall improved performance in extreme climatic conditions \& under heavy traffic conditions.

\section{DESIGN STEPS}

Mixing of crumb rubber and bitumen mix $\downarrow$

Preparation of Bituminous Mix

$\downarrow$

Marshall Stability test on the mix

\section{MATERIALS}

Table -1: Materials required for CRMB mix

\begin{tabular}{|l|l|l|}
\hline Sr. No. & Material & Content \\
\hline 1 & Bitumen & $5-5.5 \%$ \\
\hline 2 & Aggregates & $75-90 \%$ \\
\hline 3 & Crumb Rubber(30 mesh) & $5 \%, 10 \%, 15 \%, 20 \%$ \\
\hline
\end{tabular}

\section{TEST}

Before preparing the specimens for Marshall Test, it is required that following steps.

- Material proposed for use the gradation requirements of the project specifications.

- The blend combinations meet the gradation requirements of the project specifications.

- Therefore use in density and voids analysis the pulse specific gravity of all aggregate used in the blend and the specific gravity of asphalt are determined.

Two principle feature of the Marshall method of mix design are density-voids analysis and stability-flow test of the compacted test specimens. The stability of test specimen is the maximum load resistance in $\mathrm{Kg}$. that the standard test specimen will develop at $600 \mathrm{C}$ when tested. The flow is the total movement or strain occurring in the specimen between no load and maximum load during the stability test. In determining the bitumen content for a particular blend or gradation of aggregate triplicate specimen are prepared over a range of different bitumen contents (For conventional bitumen $5 \%$ to $6 \%$ and for modified bitumen $4.5 \%$ to $5.5 \%$ ). So that one is above the optimum and one is below the optimum content. Aggregate needed is about 1250 gm for each test.

\subsection{Equipment Needed}

- Pans for heating aggregates.

- Pans for mixing bitumen and aggregates.

- Electric oven for heating aggregate.

- Contains for handling bitumen and aggregates.
- Thermometer.

- Balance of $5 \mathrm{Kg}$. and $2 \mathrm{Kg}$. capacities.

- Mixing spoon.

- Spatula.

- Water bath for heating compaction hammer and mould.

- Electrically operated compactor with all accessories.

- Extrusion jack.

- Water bath at 600C.

- Gloves.

\subsection{Specimen Preparation}

(1) Number of Specimen: At least three specimens are prepared for each combination of aggregates and bitumen content.

(2)Preparation of aggregate: Aggregates are dried to temperature at $1050 \mathrm{C}-1100 \mathrm{C}$ and separation by dry sieving into desired size fractions.

(3) Sieve analysis of aggregates: Numbers of trials are done to fix the proportion of different aggregate by sieve analysis. This portion is very important in bitumen mix design.

(4) Preparation of mixing and compaction temperature: Bitumen is heated to about $1350 \mathrm{C}$ to $1450 \mathrm{C}$ so that the water vapor present in it is evaporated \& aggregates are heated to about $170^{\circ} \mathrm{C}-175^{\circ} \mathrm{C}$. Bitumen is mixed thoroughly with aggregates by manually or mechanically.

(5) Preparation of mould and hammer: Specimen mould and compaction hammer are cleaned thoroughly and mould assembly is heated in hot air oven to a temperature of about 1500C. A little grease is applied to the mould before the mix is placed in the mould.

(6) Preparation of Specimen: The amount of each size of fraction required to produce a mixed aggregate of $1200 \mathrm{gm}$. as per gradation is weighted. The required height of specimen is $63.5 \pm 1 \mathrm{~mm}$. aggregate and bitumen is heated separately to the require temperatures. Then bitumen is poured in aggregate as per requirement. Then mixture is mixed till a uniform coating of bitumen is obtained on aggregate. This is obtained at about 1500C.

(7) Compaction of the Specimen: Mould is assembled and a little grease is applied to it. Mix is transferred into 3 layers and each layer being tamped with spatula by 25 times. Then 75 blows are applied through manually or electrically operated compactor. Then same numbers of blows are applied on the other side of mould. Then the specimen is allowed to cool, once the specimen comes to room temperature de-mould is carried out.

(8) Application of water bath: Before testing mould on Marshall Apparatus, the moulds are followed to keep in the water bath for 30 to 40 minutes at $600 \mathrm{C}$. Mould should be tested within 3 to 4 minutes after taken out from water bath.

(9) Basic parameters of Marshall Test: Mould is put out on Marshall Apparatus and Marshall Stability as well as Marshall Flow is measured by proving ring and flow dial gauge respectively. The minimum value of proving ring is 1 division 
$=0.01 \mathrm{~mm}$ and flow dial gauge 1 division $=0.25 \mathrm{~mm}$. the correction factor is depends on capacity of Marshall Apparatus.

After this, the other parameters like Unit Weight (gm/cc), Specific Gravity of mix (Gmm), Air Voids (\%), Voids in mineral aggregates (\%), Voids filled with bitumen (\%), etc. are calculated by derived formulas.[2]

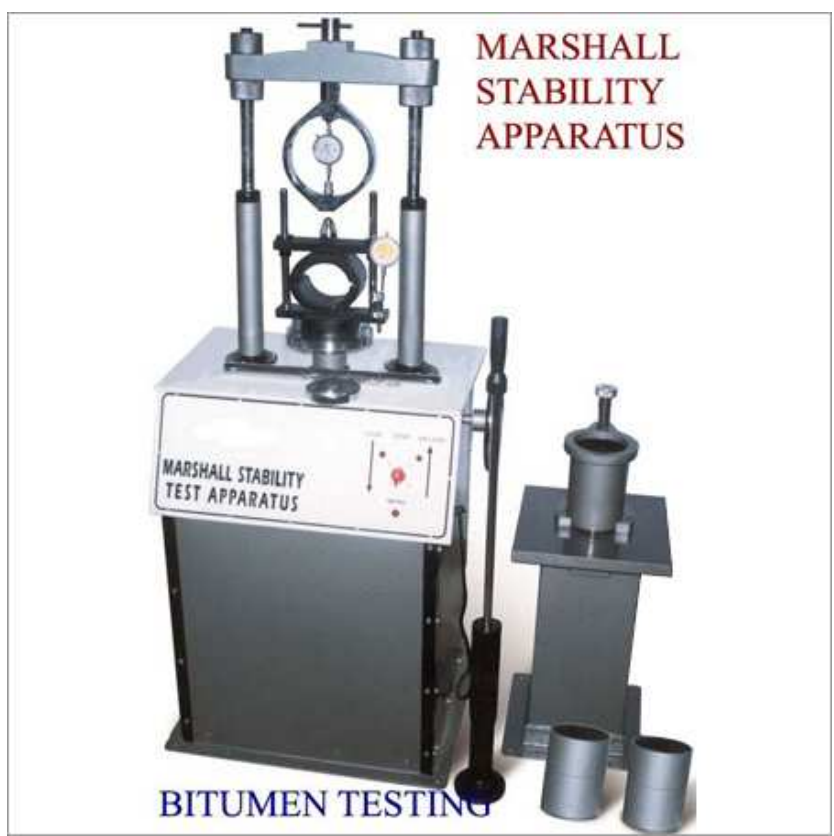

Fig -1: Marshall Stability Apparatus.

Source of figure (www.asphalttestinginstruments.com)

\section{TEST RESULTS}

Result table is provided after biographies.

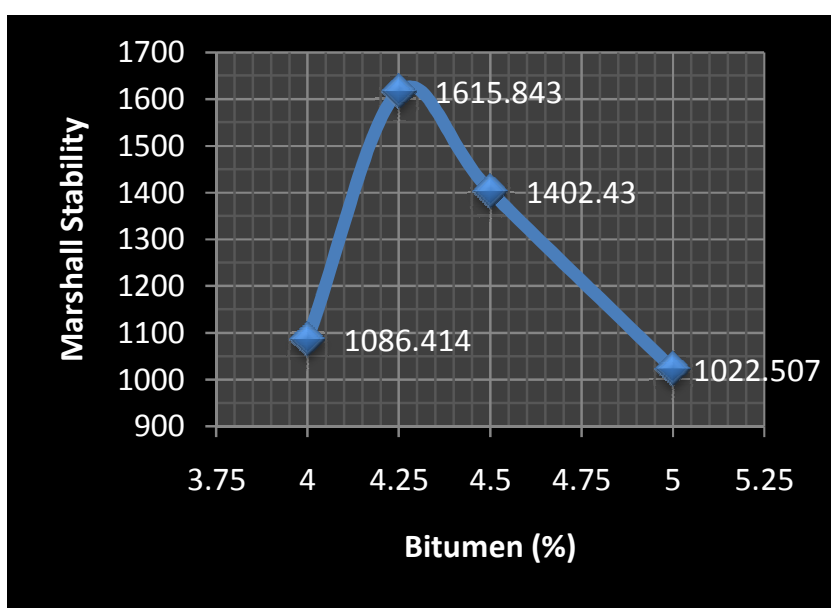

Fig 2: Marshall Stability (kg) Vs Bitumen (\%)

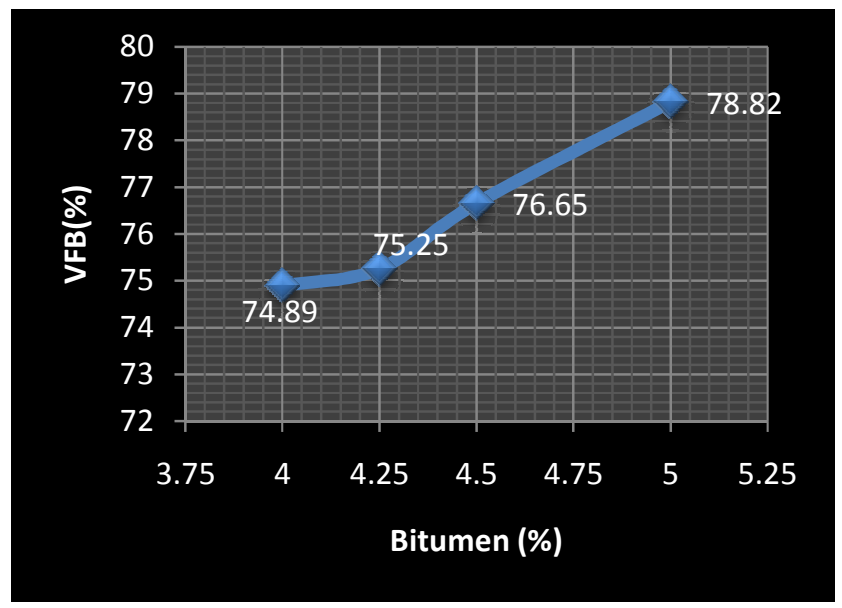

Fig 3: VFB (\%) Vs Bitumen (\%)

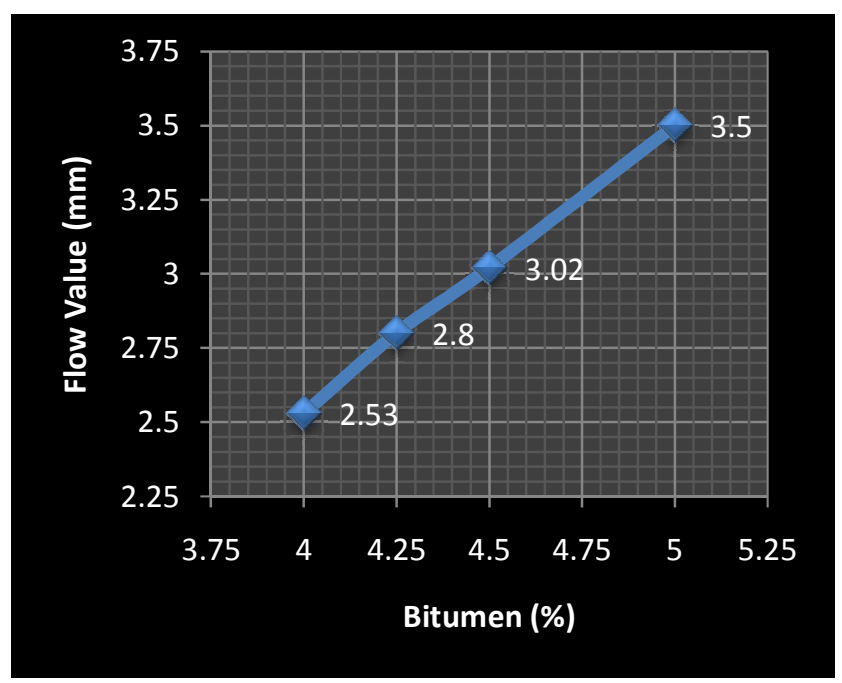

Fig 4: Flow VFB (\%) Vs Bitumen (\%)

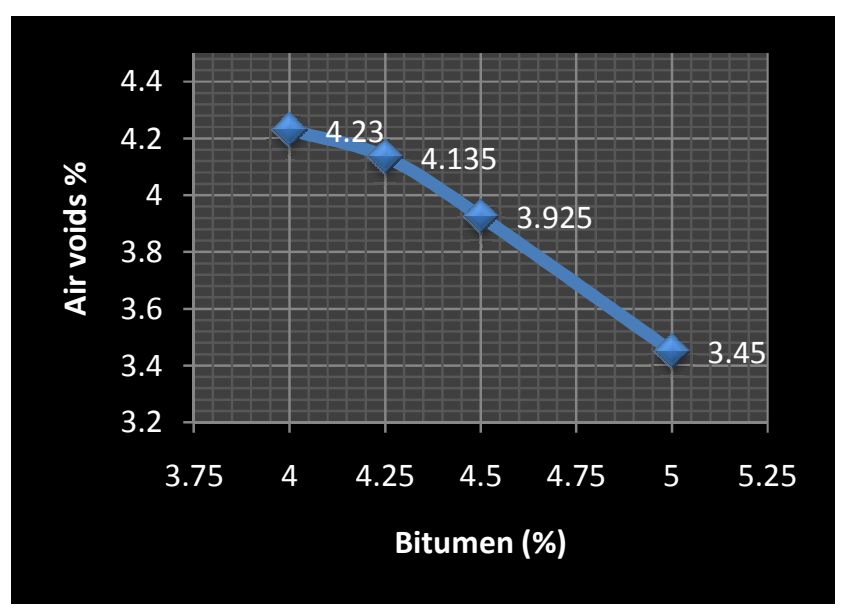

Fig 5: Air Voids (\%) Vs Bitumen (\%) 


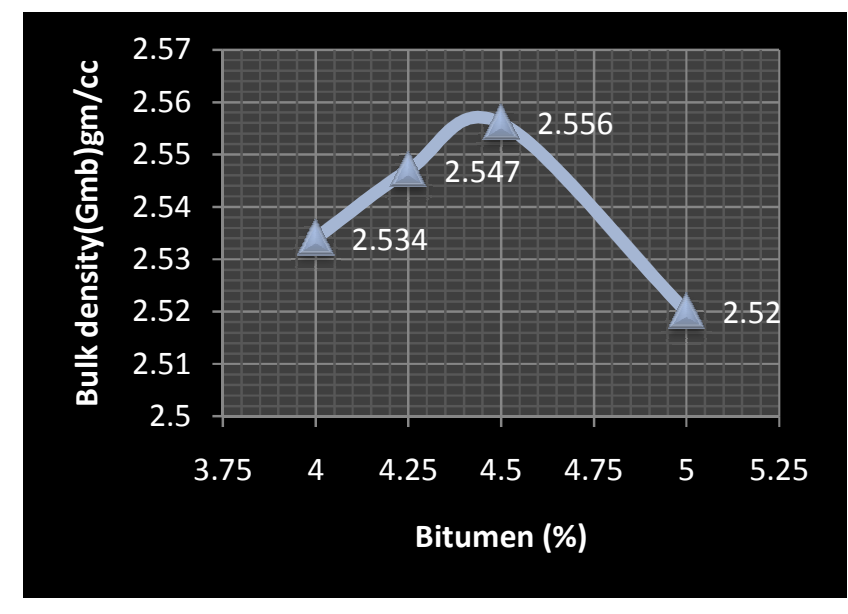

Fig 6: Bulk Density (gm/cc) Vs Bitumen (\%)

\section{CONCLUSIONS}

Crumb rubber gives the satisfactory results by using it in $15 \%$ of proportion to replace the bitumen for various tests of bitumen \& bitumen mix.Crumb rubber gives the Marshall Stability value of $1615.84 \mathrm{~kg}$ by using $15 \%$ of crumb rubber powder with bitumen mix, which is 1.6 times greater than the Marshall Stability value of conventional bitumen mix.

\section{REFERENCES}

[1]. http://www.total.co.in/pro/bitumen-home/bitumen-forroads/crumb-rubber-modified-bitumen.html

[2]. Marshall Procedures for Design and Quality Control of Asphalt Mixtures. Asphalt Paving Technology: Proceedings, vol. 54. Association of Asphalt Paving Technologists Technical Sessions, 11-13 February 1985. San Antonio, TX. pp. 265-284.

[3]. http://www.asphalttestinginstruments.com

\section{BIOGRAPHIES}

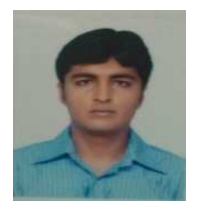

I, Harpalsinh Raol, is currently pursuing my master degree in Transportation engineering from GEC Modasa. I have done my degree engineering from SPCE Visnagar. I am in a constant endeavor to enhance my knowledge in the field of transportation engineering.

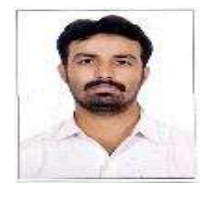

I, Abhijitsinh Parmaris currently working as a Head and assistant Professor at ShankersinhVaghelaBapu Institute of Technology. I have Completed M.Tech in Structural Design from CEPT University
I, Jitendra Jayswal, is currently pursuing my master degree in Water Resource engineering from LDCE. I have done my degree engineering from SPCE Visnagar. I am in a constant endeavor to enhance my knowledge in the field of Water Resource management.

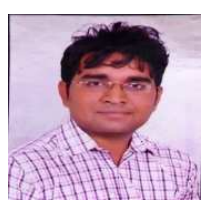

I, Dhaval M Patel, is currently pursuing my master degree in Water Resource engineering from LDCE. 
IJRET: International Journal of Research in Engineering and Technology eISSN: 2319-1163 | pISSN: 2321-7308

Table -2: Marshall Stability test result of CRMB

\begin{tabular}{|c|c|c|c|c|c|c|c|c|c|}
\hline Sr. No. & $\begin{array}{c}\text { Crumb } \\
\text { Rubber } \\
\%\end{array}$ & $\begin{array}{c}\text { Bitumen } \\
\%\end{array}$ & $\begin{array}{c}\text { Density } \\
(\mathrm{Gmb})\end{array}$ & $\begin{array}{c}\text { Maximum } \\
\text { theortical } \\
\text { Specific } \\
\text { Gravity } \\
(\mathrm{Gmm})\end{array}$ & $\begin{array}{c}\text { Air } \\
\text { void \% }\end{array}$ & $\begin{array}{c}\text { VMA } \\
\%\end{array}$ & $\begin{array}{c}\text { VFB } \\
\%\end{array}$ & $\begin{array}{c}\text { Corrected } \\
\text { Stability } \\
(\mathrm{kg})\end{array}$ & $\begin{array}{c}\text { Flow } \\
(\mathrm{mm})\end{array}$ \\
\hline 1 & 0 & 5 & 2.52 & 2.61 & 3.45 & 16.29 & 78.82 & 1022.507 & 3.5 \\
\hline 2 & 10 & 4.5 & 2.556 & 2.62 & 3.925 & 16.80 & 76.65 & 1402.43 & 3.02 \\
\hline 3 & 15 & 4.25 & 2.547 & 2.632 & 4.135 & 16.49 & 75.25 & 1615.84 & 2.8 \\
\hline 4 & 20 & 4 & 2.534 & 2.645 & 4.23 & 16.23 & 74.89 & 1086.41 & 2.53 \\
\hline
\end{tabular}

